\title{
CADEIA PRODUTIVA DE FRANGO DE CORTE: UMA ANÁLISE DE DESEMPENHO A PARTIR DA MATRIZ INSUMO-PRODUTO DE MATO GROSSO DO SUL ${ }^{1}$
}

\author{
Wesley Osvaldo Pradella Rodrigues ${ }^{2}$ \\ Daniel Massen Frainer ${ }^{3}$ \\ Antonio Sérgio Eduardo 4
}

Resumo: A cadeia produtiva de frango de corte em Mato Grosso do Sul apresenta uma estrutura de mercado semelhante à de oligopólio competitivo, com alta concentração, inexistência de diferenciação e ausência de dominação do mercado pelos agentes. Neste trabalho buscou-se analisar os efeitos de uma estrutura de mercado concentrado para o desempenho da cadeia produtiva, assim como sua relação e interação com o resto da economia estadual. A partir do background fornecido pelo modelo insumo-produto, constatou-se a baixa contribuição direta do setor para a geração de spillover dos efeitos multiplicativos do emprego (E), rendimento (R) e produção (VA). Os resultados possibilitam o melhor entendimento da cadeia produtiva de frango de corte e os reflexos de uma estrutura de mercado concentrado na economia.

Palavras-chave: Mercado imperfeito. Economia regional. Agronegócio. Frango de corte. Matriz insumo-produto.

\section{THE BROILER PRODUCTION CHAIN: AN ANALYSIS OF PERFORMANCE BASED ON MODEL INPUT-OUTPUT IN MATO GROSSO DO SUL}

Abstract: The broiler production chain in Mato Grosso do Sul has a market structure similar to that of a competitive oligopoly, with high concentration, no differentiation from and no market dominance by agents. In this work we sought to analyze the effects of a concentrated market structure for the performance of the production chain, as well as its relationship and interaction with the rest of the state economy. From the background provided by the input-product model, the sector's low direct contribution to the generation and spillover of the multiplicative effects of employment $(E)$, income $(R)$ and production (VA) was found. The results enable a better understanding of the broiler production chain and the reflexes of a market structure concentrated in the economy.

Keywords: Imperfect Market. Regional economy. Agribusiness; Broiler. Model inputoutput.

\section{LA CADENA DE PRODUCCIÓN DE BROILER: UN ANÁLISIS DE RENDIMIENTO BASADO EN EL MODELO DE ENTRADA-SALIDA EN MATO GROSSO DO SUL}

\footnotetext{
${ }^{1}$ Artigo extraído da Tese de Doutorado intitulada "Análise da Cadeia Produtiva de Frango de Corte em Mato Grosso do Sul", orientada pelo Prof ${ }^{\circ}$ Dr. Daniel Massen Frainer e defendida na Universidade Anhanguera Uniderp em março de 2020.

2 Universidade Federal de Mato Grosso do Sul, Campus de Naviraí, Naviraí, Brasil, wesley.rodrigues@ufms.br / https://orcid.org/0000-0003-1927-3271

3 Universidade Estadual de Mato Grosso do Sul, Unidade Campo Grande, Campo Grande, Brasil, danielfrainer@gmail.com / https://orcid.org/0000-0003-0813-214X

${ }^{4}$ Universidade Federal de Mato Grosso do Sul, Campus Nova Andradina, Nova Andradina, Brasil, antonio.sergio@ufms.br / https://orcid.org/0000-0003-2106-211
} 
Resumen: La cadena de producción de pollos de engorde en Mato Grosso do Sul tiene una estructura de mercado similar a la de un oligopólio competitivo, con alta concentración, sin diferenciación y sin dominio de mercado por parte de los agentes. En este trabajo, buscamos analizar los efectos de una estructura de mercado concentrada para el desempeño de la cadena de producción, así como su relación e interacción con el resto de la economía estatal. A partir de los antecedentes proporcionados por el modelo de insumo-producto, se encontró la baja contribución directa del sector a la generación y propagación de los efectos multiplicativos del empleo $(E)$, el ingreso $(R)$ y la producción (VA). Los resultados permiten una mejor comprensión de la cadena de producción de pollos de engorde y los reflejos de una estructura de mercado concentrada en la economía.

Palabras clave: Mercado imperfecto. Economía regional. Agronegocios. Pollos de engorde. Matriz de entrada-salida.

\section{Introdução}

A cadeia produtiva de frango de corte se destaca na economia brasileira e mundial pela competitividade e dinamismo dos constantes avanços tecnológicos e biotecnológicos. A competitividade pode ser expressa pelos ganhos de produtividades e, consequentemente, progressivas quedas nos custos de produção e no preço da carne de frango (COSTA et al., 2015). Atualmente a carne de frango é uma das mais produzidas e consumidas no mundo, e estima-se que até 2025, seja a principal proteína animal produzida e consumida no mundo (OECD/FAO, 2016).

O Brasil é o segundo maior produtor mundial de carne de frango, produzindo um total de 12,9 milhões de toneladas em 2016, ficando atrás apenas dos EUA, este com produção de 18,2 milhões de toneladas. E, desde 2004, ocupa a liderança mundial na exportação de carne de frango (ABPA, 2017). O estado de Mato Grosso do Sul é o oitavo maior produtor nacional, abatendo e processando 453,5 mil toneladas de carne de frango em 2017, e o sétimo maior exportador de carne de frango, exportando 173,4 mil toneladas para mais de 120 países (COMEX STAT/MDIC, 2018; SIDRA/IBGE, 2018). Em Mato Grosso do Sul a cadeia produtiva apresenta uma estrutura de mercado semelhante a oligopólio competitivo ${ }^{5}$, estando concentrada em torno de três agroindústrias processadoras (JBS Foods, BR Foods e Grupo Pluma) que atuam a montante e jusante. A montante observa-se concentração no processo de compra de insumos e criação e engorda de aves para corte, processo no qual as agroindústrias estabelecem contratos de integração com

\footnotetext{
5 “... estrutura oligopólica corresponderia aproximadamente às indústrias tradicionais de bens de consumo não duráveis, compostas em proporções variáveis de pequenas e grandes empresas nacionais e de algumas grandes empresas estrangeiras relativamente antigas. Apesar de poder haver diferenciação de produto, este não é o traço essencial para explicar o processo de acumulação e expansão do setor" (TAVARES, p.133, 2019).
} 
os produtores a fim de garantir uma oferta constante e atender as especificidades estabelecidas. Neste caso, os contratos de integração atuam como barreia à entrada de novos concorrentes, visto que as agroindústrias atuam e/ou controlam todos os elos da cadeia produtiva.

No processo a jusante, deve-se destacar o perfil exportador das empresas atuantes no Estado, as quais destinam grande parte da produção para os mercados Asiáticos e do Oriente Médio, outro aspecto importante é a concentração das exportações por parte de dois grupos empresarias (Grupo Pluma e Grupo JBS) que detém o volume total de exportações de carne de frango.

Com relação a estrutura de mercado da cadeia produtiva de frango de corte, evidencia-se a concentração das firmas, porém não se constata a dominação do mercado por nenhuma delas, aspecto este que contribui para a caracterização do setor como oligopólio. Nesse contexto, este trabalho parte da seguinte questão norteadora: Quais os impactos socioeconômicos de uma cadeia produtiva concentrada para o estado de Mato Grosso do Sul? Assim, este trabalho objetiva analisar o desempenho da cadeia produtiva de frango de corte de Mato Grosso do Sul sob as óticas do valor adicionado (VA), emprego (E) e renda (R).

A pesquisa está estruturada em cinco tópicos além da introdução. $O$ segundo tópico compreende o referencial teórico. A metodologia abordada no estudo está apresentada no terceiro tópico. O quarto tópico demonstra os resultados e discussão das análises do estudo. Por fim, o quinto e último tópico apresenta as considerações finais do trabalho.

\section{Revisão teórica: matriz insumo-produto, cadeias produtivas e ECD}

Leontief desenvolveu a metodologia de Matriz Insumo-Produto (MIP) a partir dos estudos anteriores realizados por Francis Quesnay (1696-1774) e Léon Walras (1834-1910), onde o modelo de Quesnay transforma os fluxos existentes entre as atividades da economia em quadros contábeis. Já a teoria desenvolvida por Walras utiliza um conjunto de coeficientes, onde a produção dos fatores relaciona-se com a demanda necessária para a produção de uma unidade do produto.

O método da MIP estabelece a relação entre gastos com fatores de produção e o produto resultante, permitindo que sejam quantificadas as interdependências entre os setores produtivos, destacando as transferências de bens de um setor econômico para outro (LEONTIEF, 1988; RICHARDSON, 1978). 
Zylbersztajn (2000) destaca a aplicação do método da MIP no estudo desenvolvido por Davis e Goldberg na década de 1950, do qual se originou o termo agribusiness. Neste trabalho, Davis e Goldberg analisaram o comportamento nas cadeias produtivas da soja, trigo e laranja na agricultura norte-americana, aplicando uma metodologia de análise conhecida como Commodity System Approach (CSA), a qual tem como base o uso da MIP para determinar a dependência e a intensidade das ligações intersetoriais, e em especial a participação setorial na formação do produto nacional. Dentro do enfoque da CSA, a análise de interdependência setorial está fortemente ligada à definição de estratégias das organizações que compõem a cadeia (ZYLBERSZTAJN, 2000; 2017).

$\mathrm{Na}$ mesma linha metodológica de análise surgiu, na década seguinte, o conceito francês de filière, com abordagem mais teórica, porém complementar, com base na microeconomia aplicada e em trabalhos de marketing agrícola, baseados no modelo de Organização Industrial de Bain (1968), concentrando-se os trabalhos em duas grandes abordagens, estrutura de mercado de sistemas agroalimentares e a outra abordando a industrialização agrícola (COOK e CHADDAD, 2000).

$O$ conceito de cadeia ou filière é baseado nas relações intersetoriais da economia francesa descrita desde o Tableau Economique, de Quesnay, e nas obras de Marx e Kautsky, entre outros. De acordo com Zylbersztajn (2000, 2017), o enfoque dos estudos de cadeias (filières) estão nas ações governamentais, não exclusivamente, focalizado nas estratégias das organizações.

No trabalho de Goldberg (1968), o autor limitou o uso da MIP e ampliou a análise com base no paradigma Estrutura-Conduta-Desempenho (ECD). Os trabalhos da escola francesa seguiu os mesmos passos de Goldberg, porém utilizando critérios mais descritivos nas análises de filières (TALAMINI e PEDROZO, 2004). Talamini e Pedroso destacam o consenso entre as duas abordagens, MIP e ECD, acerca da importância do estudo das relações intersetoriais na economia para a tomada de decisão, tanto no âmbito público, como no privado.

O modelo ECD parte do pressuposto de que "maior concentração da oferta (estrutura) implica maior probabilidade de colusão (conduta) e, por consequência, preços e lucros mais elevados" (MELLO, 2002, p. 497). Assumindo assim, que o poder de mercado é função crescente da concentração de empresas, e a existência de pequeno número de empresas (concorrentes) e a sua desigualdade favorecem conluios tácitos ou explícitos. 
Nesse enfoque, o desempenho do setor, o sucesso da indústria em produzir bens para os consumidores, depende da conduta das firmas com relação ao comportamento dos preços, pesquisa e desenvolvimento, publicidade e propaganda, táticas legais, entre outros. A conduta, por sua vez, depende da estrutura de mercado, fatores que determinam a competitividade no mercado, caracterizada pelo número e tamanho das firmas compradoras e vendedoras, grau físico ou subjetivo de diferenciação, a presença ou ausência de barreiras à entrada de novas firmas, entre outros (SCHERE e ROSS, 1990).

Aplicações do paradigma ECD em cadeias produtivas podem ser encontrados em diferentes trabalhos da literatura nacional e internacional, como os trabalhos de Viaene e Gellynck (1995), Bhuyan e Lopez (1997), Allen, Reeves e Mumma (1999), Carvalho e Aguiar (2005), Muller, Santos e Aguiar (2006), Harre e Pirsche (2009); Barros, Lima e Fernandes (2010), Soares et al. (2010), Caleman e Cunha (2011), Sediyama et al. (2011), Oliveira (2011), Setiawan et al. (2013), Vargas e Fiegenbaum (2014), Nzima e Dzanja (2015) e Figueiredo Junior et al. (2016). Com relação aos estudos sob a temática do frango de corte, destacam-se os trabalhos de Cunha e Dias (2006), Oliveira (2011), Yesufu e Ayanwale (2011), Mohamed et al. (2015) e Rodrigues et al. (2015).

A utilização do modelo Insumo-Produto em cadeias produtivas é tema recorrente na literatura, citando como exemplos os trabalhos de Haguenauer et al. (2001), Guilhoto et al. (2006), Torezani (2016), Gonçalves, Neves e Braga, (2015) e Fagundes et al. (2016). Porém, estes estudos apresentam foco principal em determinar a participação e os efeitos de um setor específico para a geração de emprego e/ou renda para determinada região.

Este trabalho se destaca ao partir dos pressupostos do paradigma ECD, ao qual a estrutura de mercado e a conduta influenciam o desempenho da cadeia produtiva de frango de corte de Mato Grosso do Sul, apresentando os efeitos de estrutura concentrada para o desempenho sob as óticas do valor adicionado (VA), emprego $(E)$ e rendimento $(R)$.

\section{Material e método}

A metodologia adotada neste estudo se baseia na matriz insumo-produto, que possibilita realizar uma análise detalhada dos diversos setores da economia, tanto 
os compradores como os vendedores na estrutura produtiva. Assim, para alcançar os objetivos propostos no estudo, utilizaram-se os índices de ligação setorial de Rasmussen-Hirschman, campos de influência, bem como os multiplicadores de renda, emprego e produto.

$\mathrm{Na}$ perspectiva de interdependência setorial de uma economia, pode-se avaliá-la através de índices que sintetizam as ligações para trás (backwrad linkage Uj) e para frente (forward linkage - Ui) das atividades produtivas, tal como desenvolvido por Rasmussen (1956) e Hirschman (1956). De acordo com Miller e Blair (2009) os valores calculados pelo backward linkage expressam quanto o setor demanda de outros setores da economia, enquanto o forward linkage apresenta o quanto o setor é demandado pelos outros setores. Para Porsse (2005) o índice de forward linkage de um setor i pode ser interpretado como sendo o aumento total da produção de todos os setores da economia quando ocorre o aumento unitário pela demanda final do setor i, o índice backward linkage por sua vez, pode ser interpretado como sendo o aumento da produção do setor i quando ocorre um aumento unitário na demanda final da economia. Esses índices são obtidos, respectivamente, pelas seguintes equações:

$$
\begin{aligned}
& U_{j}=\frac{n^{-1} b_{j}}{B^{*}} \\
& \mathrm{U}_{i}=\frac{n^{-1} b_{i}}{B^{*}}
\end{aligned}
$$

onde se consideram $b_{j}$ e $b_{i}$ as somas totais das colunas e das linhas da matriz B; B* o valor médio de todos os elementos dessa matriz; e o $\mathrm{n}$ representa o número de setores considerados na coluna da matriz B.

Esses índices podem ser normalizados tornando-se seu coeficiente médio em relação à média total dos coeficientes. Então, definindo-se a média de cada indicador de ligação e a média total dos coeficientes da matriz de Leontief, como expressas as equações abaixo:

$$
\begin{gathered}
\bar{U}=n^{-1} U_{j} \\
\bar{U}=n^{-2} \sum_{j=1}^{n} \sum_{i=i}^{n} \bar{B}_{i j}
\end{gathered}
$$

os índices de ligações para frente e para trás, normalizados, são obtidos calculandose, respectivamente: 


$$
\begin{aligned}
& U_{i}^{*}=\frac{\bar{U}_{i}}{\bar{U}} \\
& U_{j}^{*}=\frac{\bar{U}_{j}}{\bar{U}}
\end{aligned}
$$

Porsse (2002) destaca que a construção de índices normalizados possibilita uma melhor identificação dos setores-chave, assim indicadores normalizados com valores superiores à unidade evidenciam setores com comportamento acima da média (setor-chave).

A identificação dos setores-chave da economia baseia-se no pressuposto de que algumas atividades têm o potencial de gerar um maior crescimento através de suas ligações para trás (backward linkage) e para frente (forward linkage), estimulando o restante da economia, o que permite ser utilizada como ferramenta de planejamento econômico.

Uma abordagem complementar aos multiplicadores de impacto sobre determinadas variáveis macroeconômicas estaduais pode ser encontrados a partir da matriz de insumo-produto. Estes resultados derivados consideram as interrelações setoriais observadas na matriz de coeficientes técnicos. Para Porsse (2002) a construção de multiplicadores contribui para o processo decisório dos policy makers ao definirem as políticas públicas de desenvolvimento regional.

De forma geral, um multiplicador mede o impacto global de variações na demanda final do setor j sobre uma variável econômica de interesse, ou seja, medem o impacto de um aumento unitário na demanda final de um determinado setor sobre todos os setores que possuem algum grau de ligação com este (PORSSE, 2002; COSTA et al. 2005). Esse efeito global pode ser decomposto em impactos direto, indireto e efeito-renda, como destaca Feijó et al. (2017):

Quadro 01- Os multiplicadores econômicos resultantes da matriz de insumo-produto

\begin{tabular}{|ll|}
\hline Multiplicador direto & $\begin{array}{l}\text { Mede o impacto de variações na demanda final do j-ésimo } \\
\text { setor, considerando somente as atividades que fornecem } \\
\text { insumos diretos a esse setor. }\end{array}$ \\
\hline Multiplicador indireto & $\begin{array}{l}\text { Mede o impacto de variações na demanda final do j-ésimo } \\
\text { setor, considerando somente as atividades que fornecem } \\
\text { insumos indiretos a esse setor. }\end{array}$ \\
\hline $\begin{array}{l}\text { Multiplicador efeito-renda } \\
\text { (induzido) }\end{array}$ & $\begin{array}{l}\text { Mede o impacto de variações na demanda final do j-ésimo } \\
\text { setor, considerando a variação adicional da demanda } \\
\text { provocada pelo incremento no nível de rendimentos da } \\
\text { economia quando um setor é estimulado. }\end{array}$ \\
\hline
\end{tabular}




\section{Multiplicador total}

Mensura o impacto da variação de demanda final do $j-$ ésimo setor, considerando as atividades que fornecem insumos diretos e indiretos para o setor.

Fonte: elaborado a partir de Feijó et al. (2017):

Neste trabalho, serão construídos multiplicadores para três variáveis macroeconômicas: valor adicionado (VA), emprego $(E)$ e renda $(R)$ (remuneração do pessoal ocupado). Os multiplicadores totais são encontrados somando-se os três multiplicadores relacionados acima.

Tomando-se como exemplo a variável emprego, o multiplicador direto $\left(e_{j}^{D}\right)$ é aquele que mostra o requerimento de emprego por unidade de produto de cada setor, como expresso na Equação 7.

$$
e_{j}^{D}=\frac{E_{j}}{X_{j}}
$$

onde $E_{j}$ e $X_{j}$ são, respectivamente, o nível de emprego e de produção no setor j.

O multiplicador direto e indireto do emprego mostra o impacto de um aumento na demanda final do setor $\mathrm{j}$ sobre o emprego total, dado o encadeamento setorial do modelo aberto de Leontief.

$$
e^{D I}=e^{D} Z
$$

onde $\mathrm{e}^{\mathrm{DI}}$ representa $\mathrm{o}$ vetor do multiplicador direto e indireto do emprego; $\mathrm{e}^{\mathrm{D}}$ representa o vetor dos coeficientes do emprego (emprego por unidade de produto em cada setor) e $Z$ representa a matriz de Leontief.

O multiplicador total do emprego (direto, indireto e efeito-renda) mostra 0 impacto de um aumento na demanda final do setor j sobre o emprego total, dado o encadeamento setorial do modelo fechado.

$$
e^{D I R}=e^{D \bar{Z}}
$$

onde $\mathrm{e}^{\mathrm{DIR}}$ representa o vetor do multiplicador direto e indireto do emprego e $\bar{Z}$ representa a matriz de Leontief do modelo fechado. Assim, a partir do multiplicador direto obtido pela equação 2 , os multiplicadores indireto $\left(e^{\prime}\right)$ e efeito-renda $\left(e^{R}\right)$ são deduzidos pelas expressões:

$$
\begin{gathered}
e^{I}=e^{D I}-e^{D} \\
e^{R}=e^{D I R}-e^{I}-e^{D}=e^{D I R}-e^{D I}
\end{gathered}
$$


Os multiplicadores direto, indireto e efeito-renda para o VA e a renda são calculados de forma análoga aos procedimentos descritos acima.

Índices de Rasmussen-Hirschman, proposta por Sonis, Hewings e Guo (1996) é utilizar o conceito de campo de influência, pois permite mensurar os efeitos sinérgicos das alterações nos coeficientes técnicos da MIP. A análise permite observar como as mudanças dos coeficientes diretos se distribuem no sistema econômico, determinando as relações entre os setores em que seriam mais influentes dentro do processo produtivo (HADDAD, 1995; KALUFF, KURESKI, 2014).

Para se calcular o campo de influência, é necessária a utilização da matriz de coeficientes técnicos $(A)$, de uma matriz de variações incrementais nos coeficientes diretos de insumos $(E)$ e da matriz inversa de Leontief $\left\{B=(I-A)^{-1}\right\}$.

Para avaliar o impacto dessas variações em cada um dos elementos da matriz $\mathrm{A}$, deverá ocorrer uma pequena variação $\varepsilon$, em cada setor isoladamente, ou seja, $\Delta \mathrm{A}$ é uma matriz, tal que $\mathrm{E}=\left|\varepsilon_{i j}\right|$, tal que:

$\varepsilon_{i j}=\left\{\begin{array}{cc}\varepsilon \text { se } i=i_{j}, & j=j_{i} \\ 0 \text { se } i \neq i_{j}, & j \neq j_{i}\end{array}\right.$

Nesta situação, uma variação de magnitude $\Delta \mathrm{A}$ nos coeficientes da matriz $\mathrm{A}$ resulta numa matriz de coeficientes técnicos: $A=A+\Delta A$. Logo, a matriz inversa de Leontief pode ser reescrita como: $B^{*}=(I-A-\Delta A)^{-1}$.

O campo de influência de cada coeficiente é aproximadamente igual a (12):

$$
F\left(\varepsilon_{i j}\right)=\frac{\left(B^{*}-B\right)}{s_{i j}}
$$

Sendo assim, a influência total de cada coeficiente técnico, ou de cada elo da matriz insumo produto, é dada por (13):

$$
S_{i j}=\sum_{k-1}^{n} \sum_{l-1}^{n}\left[f_{k l}\left(\varepsilon_{i j}\right)\right]^{2}
$$

Em que $S_{i j}$ é o valor associado à matriz e que, portanto, permite desenvolver uma hierarquia dos coeficientes técnicos baseada em seus campos de influência, de forma que os coeficientes diretos que possuírem os maiores valores serão aqueles com os maiores campos de influência dentro da economia (Guilhoto, 2004; Kaluff; Kureski, 2014). 
Os dados deste estudo foram obtidos por meio da matriz insumo-produto referente ao estado de Mato Grosso do Sul, do ano de 2015 elaborada por Frainer et al. (2020, no prelo), composta por 60 setores; foi feita a compatibilização em 11 setores (Apêndice II). São eles: (1) Cadeia de frango de corte; (2) Agropecuária sem Aves; (3) Extrativa mineral; (4) Alimentos e Bebidas; (5) Indústria de transformação; (6) SIUP; (7) Construção civil; (8) Comércio; (9) Transporte e Armazenagem; (10) Alojamento e Alimentação; (11) Outros serviços.

Morimoto (1970), Guilhoto (2004) e Mendes, Pereira e Teixeira (2011) destacam que ao se agregarem setores, há um viés de agregação, isto é, uma diferença entre o vetor de produção total do sistema agregado e o vetor obtido pela agregação do total da produção do sistema regional não-agregado. Contudo, isso não inviabiliza o estudo, pois os efeitos da agregação somente se tornam relevantes quando há uma redução muito expressiva do número de setores da matriz original.

\section{Resultados e discussão}

Encadeamento produtivo e setores chaves

Os índices de ligação permitem identificar quais setores possuem maior poder de encadeamento dentro da economia, ligações estas que podem ser tanto para frente como para trás, isto é, a quantidade de produtos demanda de outros setores da economia por um setor e quanto um setor demandaria dos outros, respectivamente (GUILHOTO, 2004). Os resultados obtidos pelos índices de ligação para os 11 setores considerados na matriz insumo-produto regional de Mato Grosso do Sul em 2015 podem ser observados na Tabela 1.

Tabela 1- Índices de ligação da Cadeia de frango de corte de Mato Grosso do Sul, 2015 (modelo aberto)

\begin{tabular}{lcll}
\hline \multicolumn{1}{c}{ Setor } & BL & FL & Orientação \\
\hline Cadeia de frango de corte & 0,52 & 0,46 & Sem ligação \\
Agropecuária sem Aves de corte & 1,04 & 1,83 & Setor-chave \\
Extrativa mineral & 1,04 & 0,62 & Para trás \\
Alimentos e Bebidas & 1,56 & 0,86 & Para trás \\
Indústria de transformação & 1,24 & 2,62 & Setor-chave \\
SIUP & 0,91 & 0,80 & Sem ligação \\
Construção civil & 1,08 & 0,55 & Para trás \\
Comércio & 0,82 & 0,52 & Sem ligação \\
Transporte e Armazenagem & 1,10 & 0,83 & Para trás \\
Alojamento e Alimentação & 1,01 & 0,47 & Para trás \\
\hline
\end{tabular}




\begin{tabular}{llll}
\hline Outros serviços & 0,69 & 1,44 & Para frente \\
\hline
\end{tabular}

Fonte: elaboração própria com base nos dados da pesquisa.

Como observado na Tabela 1, os setores de Indústria de transformação e Agropecuária sem Aves de corte se mostraram como setores-chaves para 0 crescimento da economia, pois produzem impactos diretos e indiretos tanto no emprego como na renda do Estado.

Com relação ao encadeamento para frente, que representa os setores mais dinâmicos da economia, pois representam os mais importantes vendedores, nesse sentido, destaca-se apenas o setor Outros serviços. Complementando a análise, os índices de ligação para trás representam os principais setores compradores, destacam-se os setores de Extração mineral; Alimentos e bebidas, Construção civil, Transporte e armazenagem, Alojamento e alimentação. A Cadeia de frango de corte apresentou baixa relação com os demais setores da economia, não podendo ser caracterizado como setor-chave, ou seja, o setor possui baixa capacidade de gerar spillover nos demais setores da economia. A próxima seção apresenta a relação existente entre os setores da economia sul-mato-grossense.

Campo de Influência

Como os índices de Rasmussen-Hirschman não permitem visualizar os principais elos dentro da economia, calcularam-se os campos de influência, pois descrevem como se distribuem as mudanças dos coeficientes diretos na economia, permitindo identificar quais as relações entre os setores, conforme apresentado na Figura 01. 
Figura 01- Campo de influência na Cadeia de frango de corte de Mato Grosso do Sul, 2015.

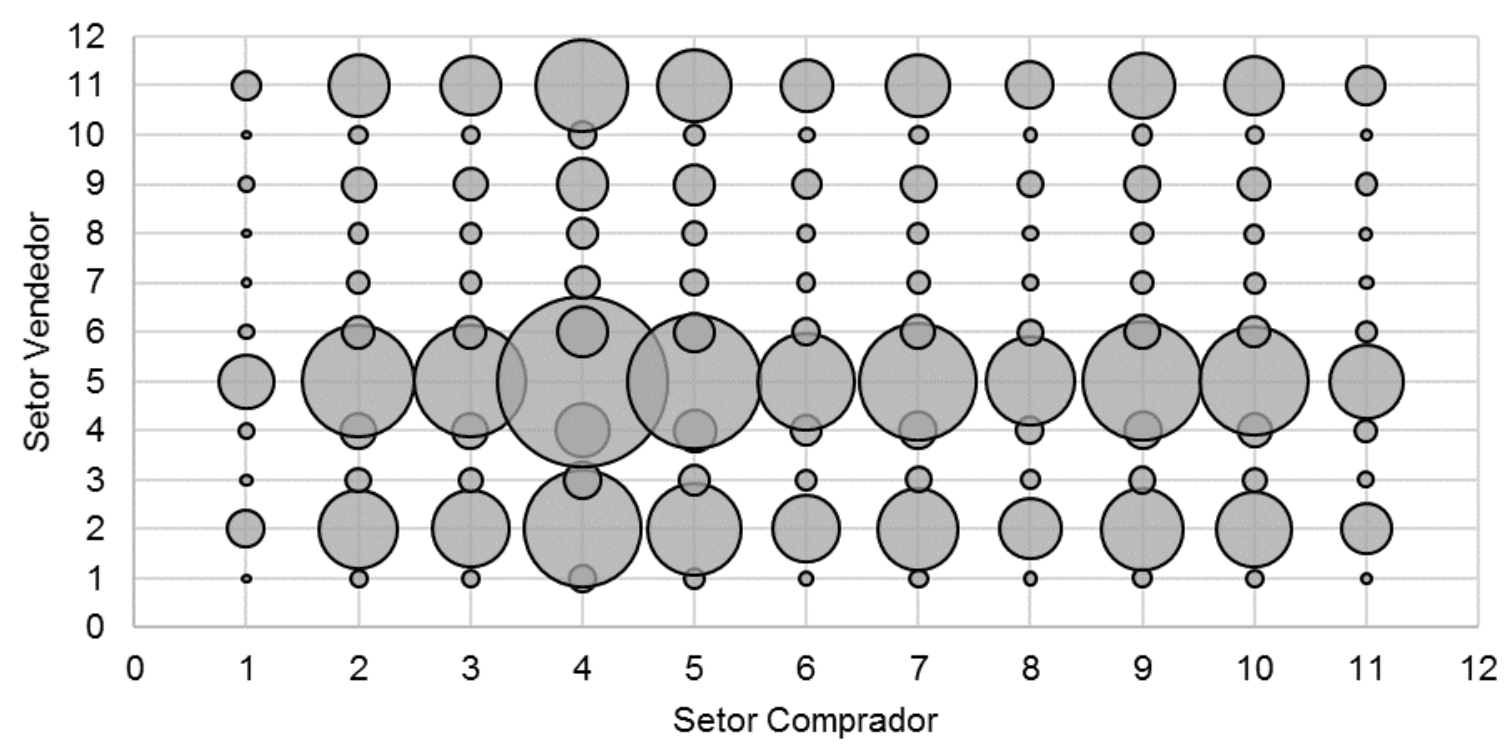

Fonte: elaboração própria com base nos dados da pesquisa.

Nota: 1.Cadeia de frango de corte; 2. Agropecuária sem Aves de corte; 3. Extrativa mineral; 4. Alimentos e Bebidas; 5. Indústria de transformação; 6. SIUP; 7. Construção civil; 8. Comércio; 9. Transporte e Armazenagem; 10. Alojamento e Alimentação e 11. Outros serviços.

Conforme Haddad (1995), a simultânea dos dois métodos é essencial para a obtenção de melhores resultados de políticas industriais. As políticas setoriais que induzam ao crescimento econômico deveriam estar direcionadas para os setores considerados estratégicos, os quais apresentam maiores campos de influência e elevado poder propagador de alterações no sistema econômico, além de um alto poder de encadeamento para trás e para frente (setores chave), e que se caracterizam como compradores de insumos regionais.

Como se observa na Figura 1, caso haja uma pequena variação na matriz de coeficiente técnico o setor Indústria de transformação (5) é o que mais propagaria essas variações no sistema econômico. A Indústria de transformação é um dos setores que mais vendem e compram dos demais setores, fato este que corrobora para seu dinamismo.

A Cadeia de frango de corte, que é foco deste estudo, apresentou baixa relação em termos de compra e venda, possuindo maior relação com o setor de Alimentos e Bebidas (4) e Indústria de transformação (5). 
Além disso, por meio do campo de influência podem-se verificar as demais interações que ocorrem na economia, com destaque para Agropecuária sem Aves de corte (2), Outros serviços (11), Alimentos e Bebidas (4), Transporte e Armazenagem (9) e SIUP (6). Deve-se destacar que, quanto maior for a bolha, mais forte é a relação que o setor possui com o outro.

Análise da Geração de Emprego, Renda e Produto na economia

Com intuito de mensurar os impactos das modificações na demanda final sobre a produção, renda e geração de empregos, dos setores, em especial a Cadeia de frango de corte, calcularam-se os multiplicadores do tipo 1 e 2 , bem como os impactos diretos e indiretos da demanda final sobre o pessoal ocupado e sobre as remunerações.

Tabela 02- Multiplicadores do tipo 1 de emprego, salário e produção da Cadeia de frango de corte em Mato Grosso do Sul, 2015

\begin{tabular}{l|cc|cc|cc}
\hline \multirow{2}{*}{\multicolumn{1}{c|}{ Setor }} & \multicolumn{2}{c|}{ Emprego } & \multicolumn{2}{c|}{ Remuneração } & \multicolumn{2}{c}{ Produção } \\
\cline { 2 - 7 } & Valor & Rank & Valor & Rank & Valor & Rank \\
\hline Cadeia de frango de corte & 211,83 & 11 & 3,58 & 11 & 20,07 & 11 \\
Agropecuária sem Aves & 1869,86 & 5 & 31,64 & 7 & 177,19 & 6 \\
Extrativa mineral & 2350,15 & 2 & 52,81 & 2 & 368,84 & 1 \\
Alimentos e Bebidas & 2200,85 & 4 & 39,47 & 5 & 242,07 & 3 \\
Industria de transformação & 3332,53 & 1 & 71,88 & 1 & 351,03 & 2 \\
SIUP & 1323,19 & 7 & 29,16 & 8 & 139,30 & 8 \\
Construção civil & 1473,39 & 6 & 32,70 & 6 & 162,04 & 7 \\
Comércio & 704,97 & 9 & 16,78 & 9 & 77,45 & 9 \\
Transporte e Armazenagem & 2339,57 & 3 & 40,92 & 4 & 191,14 & 5 \\
Alojamento e Alimentação & 1318,13 & 8 & 46,84 & 3 & 229,68 & 4 \\
Outros serviços & 519,19 & 10 & 15,59 & 10 & 77,31 & 10 \\
\hline
\end{tabular}

Fonte: elaboração própria com base nos dados da pesquisa.

Por meio da Tabela 2, verifica-se que a Cadeia de frango de corte foi um dos que apresentaram menor multiplicador da produção, isto é, caso houvesse um aumento de 1000 unidades monetárias na demanda final do setor, levaria a um aumento de 20,07 unidades monetárias na produção da economia, ao passo que o setor Extrativa mineral aumentaria a produção em 368,84 unidades monetárias.

O mesmo comportamento do setor pode ser observado em relação aos multiplicadores de emprego e renda, isto é, caso houvesse um aumento de 1000 unidades monetárias na demanda final do setor, levaria a um aumento de 211,83 
empregos e 3,58 unidades monetárias na renda. Contudo a Indústria de transformação seria a maior beneficiada, com a possível geração de 3332,53 postos de trabalhos e acréscimo de 71,88 unidades monetárias na economia do Estado.

Em relação ao impacto direto e indireto dos setores na demanda final sobre o emprego, remuneração e produção, a Tabela 3 destaca os principais resultados. Ao se analisarem os efeitos diretos sobre o emprego, observa-se que os setores Indústria de transformação, Extrativa mineral e Transporte e armazenamento, são os mais importantes geradores de empregos diretos, com relação os empregos indiretos, o setor de Alimentos e Bebidas se destaca como maior gerador de postos de trabalhos aos setores que fornecem insumos para a sua produção.

Tabela 03- Multiplicadores do tipo 1, efeitos diretos e indiretos de emprego e remuneração da Cadeia de frango de corte em Mato Grosso do Sul, 2015

\begin{tabular}{l|cc|cc}
\hline \multirow{2}{*}{\multicolumn{1}{c|}{ Setor }} & \multicolumn{2}{c|}{ Emprego } & \multicolumn{2}{c}{ Remuneração } \\
\cline { 2 - 5 } & Direto & Indireto & Direto & Indireto \\
\hline Cadeia de frango de corte & 60,78 & 151,04 & 0,49 & 3,09 \\
Agropecuária sem Aves & 536,56 & 1333,30 & 4,37 & 27,27 \\
Extrativa mineral & 1153,52 & 1196,63 & 26,95 & 25,86 \\
Alimentos e Bebidas & 266,63 & 1934,22 & 5,67 & 33,80 \\
Industria de transformação & 1630,35 & 1702,18 & $36,7.6$ & 35,12 \\
SIUP & 516,88 & 806,31 & 11,23 & 17,93 \\
Construção civil & 5,90 & 1467,49 & 0,74 & 31,96 \\
Comércio & 51,46 & 653,51 & 2,58 & 14,20 \\
Transporte e Armazenagem & 893,97 & 1445,60 & 10,38 & 30,54 \\
Alojamento e Alimentação & 487,13 & 831,00 & 30,92 & 15,91 \\
Outros serviços & 203,66 & 315,54 & 7,94 & 7,65 \\
\hline
\end{tabular}

Fonte: elaboração própria com base nos dados da pesquisa.

A renda direta também foi responsável por estes mesmos setores, porém, agora, com uma participação do setor de Alojamento e alimentação. A Cadeia de frango de corte não se destacou como esses setores, mas ao se verificar o efeito indireto, observa-se a capacidade de geração de impacto aos setores relacionados a sua atividade.

A partir do modelo de Leontief fechado, obteve-se os multiplicadores efeitorenda (induzido), o qual mensura o impacto da demanda final de um determinado setor, considerando adicionalmente o efeito da geração de renda e do consumo das famílias. A Tabela 4 apresenta o efeito induzido para a geração de emprego, remuneração e renda. 
Tabela 04- Multiplicadores do tipo 2 de emprego, salário e produção da Cadeia de frango de corte em Mato Grosso do Sul, 2015

\begin{tabular}{l|c|c|c|c|c|c}
\hline \multirow{2}{*}{\multicolumn{1}{c|}{ Setor }} & \multicolumn{2}{c|}{ Emprego } & \multicolumn{2}{c|}{ Remuneração } & \multicolumn{2}{c}{ Produção } \\
\cline { 2 - 7 } & Valor & Rank & Valor & Rank & Valor & Rank \\
\hline Cadeia de frango de corte & 217,85 & 11 & 3,72 & 11 & 20,77 & 11 \\
Agropecuária sem Aves & 1923,03 & 5 & 32,84 & 7 & 183,33 & 6 \\
Extrativa mineral & 2438,89 & 2 & 54,82 & 2 & 379,08 & 1 \\
Alimentos e Bebidas & 2267,18 & 4 & 40,98 & 5 & 249,73 & 3 \\
Industria de transformação & 3453,31 & 1 & 74,62 & 1 & 364,96 & 2 \\
SIUP & 1372,19 & 8 & 30,27 & 8 & 144,95 & 8 \\
Construção civil & 1528,34 & 6 & 33,94 & 6 & 168,38 & 7 \\
Comércio & 733,16 & 9 & 17,41 & 9 & 80,70 & 9 \\
Transporte e Armazenagem & 2408,32 & 3 & 42,47 & 4 & 199,07 & 5 \\
Alojamento e Alimentação & 1396,83 & 7 & 48,62 & 3 & 238,76 & 4 \\
Outros serviços & 545,39 & 10 & 16,18 & 10 & 80,33 & 10 \\
\hline
\end{tabular}

Fonte: elaboração própria com base nos dados da pesquisa.

Considerando o consumo das famílias ao sistema produtivo, percebe-se que o multiplicador de produção continuou a ter a Indústria de transformação como principal setor produtivo da economia do Estado, seguido pelo setor de Extração mineral e Alojamento e alimentação. A Cadeia de frango de corte continuou a ter uma relação baixa em termos de multiplicadores de produção, emprego e remuneração.

Em grande parte, observa-se que os setores permaneceram na mesma classificação, o que se verifica é que a diferença entre os dois multiplicadores tipo 1 e tipo 2 não foi expressiva para alguns dos setores, em termos de ranking, ao passo que não ocorreu alterações significativas.

Analisando os impactos diretos, indiretos e induzidos que servem de base para o multiplicador tipo 2 (Tabela 5), observa-se que um aumento expressivo do efeito induzido para o setor Industria de transformação, destacando a importância do setor para a economia do Estado.

Tabela 05- Multiplicadores do tipo 2, efeitos diretos, indiretos e induzido de emprego e remuneração da Cadeia de frango de corte em Mato Grosso do Sul, 2015

\begin{tabular}{l|c|c|c|c|c|c}
\hline \multirow{2}{*}{ Setor } & \multicolumn{3}{c|}{ Emprego } & \multicolumn{3}{c}{ Remuneração } \\
\cline { 2 - 7 } & Direto & Indireto & Induzido & Direto & Indireto & Induzido \\
\hline Cadeia de frango de corte & $\mathbf{6 0 , 7 8}$ & $\mathbf{1 5 1 , 0 4}$ & $\mathbf{6 , 0 2}$ & $\mathbf{0 , 4 9}$ & $\mathbf{3 , 0 9}$ & $\mathbf{0 , 1 4}$ \\
Agropecuária sem Aves & 536,56 & 1333,30 & 53,16 & 4,37 & 27,27 & 1,20 \\
Extrativa mineral & 1153,52 & 1196,63 & 88,74 & 26,95 & 25,86 & 2,01 \\
Alimentos e Bebidas & 266,63 & 1934,22 & 66,33 & 5,67 & 33,80 & 1,50
\end{tabular}


Industria de transformação

SIUP

Construção civil

Comércio

Transporte e Armazenagem

Alojamento e Alimentação

Outros serviços

\begin{tabular}{c|c|c|c|c|c}
1630,35 & 1702,18 & 120,78 & 36,76 & 35,12 & 2,73 \\
516,88 & 806,31 & 49,00 & 11,23 & 17,93 & 1,11 \\
5,90 & 1467,49 & 54,94 & 0,74 & 31,96 & 1,24 \\
51,46 & 653,51 & 28,19 & 2,58 & 14,20 & 0,64 \\
893,97 & 1445,60 & 68,75 & 10,38 & 30,54 & 1,56 \\
487,13 & 831,00 & 78,70 & 30,92 & 15,91 & 1,78 \\
203,66 & 315,54 & 26,19 & 7,94 & 7,65 & 0,59 \\
\hline
\end{tabular}

Fonte: elaboração própria com base nos dados da pesquisa.

A cadeia de frango de corte possui como principal modificação o impacto indireto, justamente por considerar a demanda final como endógena, isso permite notar a relação com a geração de emprego e renda indireta, sendo favorável para a economia, pois contribui para o crescimento dos demais setores da economia.

\section{Conclusão}

Este artigo foi realizado com o objetivo de analisar os impactos da cadeia produtiva de frango de corte na economia de Mato Grosso do Sul sob as óticas do valor adicionado (VA), emprego $(E)$ e renda $(R)$, considerando o ano de 2015. Para tal finalidade, utilizou-se a metodologia de insumo-produto, em que foi possível identificar os setores representativos dessa cadeia produtiva. A metodologia de matriz insumo-produto possibilitou o entendimento dos fluxos intersetoriais de bens e serviços, o que contribuiu para entender como a produção da atividade influencia a estrutura produtiva estadual.

Em termos dos resultados obtidos, o artigo revelou que a cadeia produtiva possui baixo poder de encadeamento produtivo com os demais setores da economia estadual, que representando a baixa capacidade de gerar spillover nos demais setores econômicos.

Tais resultados puderam ser melhor complementados através da análise do campo de influência, por esta permitir identificar os principais fluxos intersetoriais. Nesse sentido, a cadeia produtiva apresentou forte relação na sua atuação como vendedor de insumo para os setores de Alimentos e Bebidas e Industria de transformação. Entretanto, apesar da cadeia produtiva ter apresentado baixo poder de encadeamento produtivo, as alterações ocorridas na cadeia produtiva causarão impactos diretos nos setores de Alimentos e Bebidas e Industria de transformação.

Outra questão que cabe ser mencionada é o fato dessa atividade impulsionar além da produção, o emprego e a renda. Os resultados mostram que a cadeia 
produtiva de frango de corte apresentou multiplicadores e geradores moderados para essas atividades. Os efeitos indiretos representaram a maior parte desse impacto, sinalizando que os efeitos que se dissemina na economia é maior nos setores que possui maior poder de influência do que na própria cadeia produtiva.

Conclui-se que a cadeia produtiva de frango de corte de Mato Grosso do Sul impacta de forma pouco expressiva na economia estadual, tanto no âmbito produtivo, quanto na forma de renda e geração de empregos.

Deste modo, a partir dos resultados aqui presente é possível inferir que o pouco impacto da cadeia produtiva de frango de corte na economia estadual é fruto do modelo de negócios praticado pelas três agroindústrias processadoras (JBS Foods, BR Foods e Grupo Pluma) atuantes na cadeia produtiva, o qual restringem suas atividades no Estado para, basicamente, as relações econômicas entre os criadores e a agroindústria processadora, limitando assim o maior encadeamento intersetoriais a nível estadual.

\section{REFERÊNCIAS}

ABPA, ASSOCIAÇÃO BRASILEIRA DE PROTEINA ANIMAL. Relatório Anual 2017. Disponível em: <http://abpa-br.com.br/storage/files/relatorio-anual-2018.pdf>. Acesso em: 10 mar. 2018.

ALLEN, A. J.; REEVES, J.; MUMMA, G. Structure, Conduct, and Performance changes in the U.S. Agricultural commodity trucking industry. Journal of Food Distribution Research, Seattle, v.1, p.31-33, 1999.

BAIN, J. S. Organization Industrial. New York: Wiley, 1968.

BARROS, F. L.; LIMA, J. R.; FERNANDES, R. A. Análise da Estrutura de Mercado na cadeia produtiva do leite no período de 1998 a 2008. Revista de Economia e Agronegócio, Viçosa, v.8, n.2, p.177-198, 2010.

BHUYAN, S.; LOPEZ, R. A. Oligopoly Power in the Food and Tobacco Industries. American. Journal of Agricultural Economics, Banbury, v.79, n.3, p.1035-1043, 1997.

BREITENBACH, R.; SOUZA, R. S. Estrutura, conduta e governança na cadeia produtiva do leite: um estudo multicaso no Rio Grande do Sul. Revista Eletrônica de Administração, Porto Alegre, v. 21, n.3, p.750-781, 2015. doi:10.1590/1413-2311.0372014.53598

CALEMAN, S. M.; CUNHA, C. F. Estrutura e conduta da agroindústria exportadora de carne bovina no Brasil. Organizações Rurais \& Agroindustriais, Lavras, v.13, n.1, p.93-108, 2011.

CARVALHO, L. H.; AGUIAR, D. R. Concentração de mercado e poder de monopsônio na indústria brasileira de esmagamento de soja. Revista de Economia e Agronegócio, Viçosa, v.3, n.3, 2005.

COOK, M. L.; CHADDAD, F. R. Agroindustrialization of the global agrifood economy: bridging development economics and agribusiness research. Agricultural Economics, Milwaukee, v.23, p.207-218, 2000. 
COOK, M. L.; CHADDAD, F. R. Agroindustrialization of the global agrifood economy: bridging development economics and agribusiness research. Agricultural Economics, Milwaukee, v.23, p.207-218, 2000.

COSTA, E. D.; JÚNIOR, I. T.; BEZERRA, J. F.; MELO, M. V. Matriz de Insumo-Produto de Pernambuco para 1999: metodologia de cálculo e subsídios ao planejamento regional. Economia Aplicada, Ribeirão Preto, v.9, n.4, p.595-621, 2005.

COSTA, L. D. S.; GARCIA, L. A. F.; BRENE, P. R. A. Panorama do setor de frango de corte no Brasil e a participação da indústria avícola paranaense no complexo dado alto grau de competividade. Anais IV Simpósio Internacional de Gestão de Projetos, Inovação e Sustentabilidade, São Paulo, 2015.

CUNHA, D. A.; DIAS, R. S. Análise do segmento exportador da avicultura brasileira no período de 1996 a 2004. Revista de Economia e Agronegócio, Viçosa, v.4, n.1, p.63-74. 2006. doi:10.25070/rea.v4i1.74

FAGUNDES, M. B., DIAS, D. T., FIGUEIREDO, A. M.R., PITALUGA, C. M. Interligações setoriais e composição do produto, demanda e renda da agropecuária de Mato Grosso do Sul: uma aplicação da matriz insumo-produto. Contextus Revista Contemporânea de Economia e Gestão, Fortaleza, v.14, n.1, p.58-82, 2016.

FEIJÓ, C. A. (Orgs). Contabilidade social: referência atualizada das contas nacionais do Brasil. Rio de Janeiro: Elsevier, 5 ed., 2017.

FIGUEIREDO JUNIOR, H. S., et al. Evaluating strategies for honey value chains in Brazil using a value chain structure-conduct-performance (SCP) framework. International Food and Agribusiness Management Review, West Lafayette, v.19, n.3, p.225-250, 2016.

FRAINER, D. M., et al. Matriz insumo-produto de Mato Grosso do Sul 2015: construção e análise dos principais indicadores econômicos. Revista de Desenvolvimento Econômico, v. 2, n. 46, 2020 (no prelo).

GOLDBERG, R. A. Agribusiness coordination: a systems approach to the wheat, soybean, and Florida orange economies. Boston: Harvard University, 1968.

GONÇALVES, M. F., NEVES, M. C., BRAGA, M. J. O setor rural no nordeste brasileiro: uma análise à luz da matriz de insumo-produto. Revista Economia e Desenvolvimento, Santa Maria, v.14, n.1, p.25-43, 2015.

GUILHOTO, J. J. M. Análise de insumo - produto: teoria e fundamentos. São Paulo: USP, 2004.

GUILHOTO, J. J., SOLVEIRA, F. G., ICHIHARA, S. M., AZZONI, C. R. A importância do agronegócio familiar no Brasil. Revista de Economia e Sociologia Rural, Brasília, v.44, n.3, p.355-382, 2006. doi:10.1590/S0103-20032006000300002

GUILHOTO, J.J.M; HEWINGS, G. J. D.; SONIS, M. Linkages and multipliers in a multiregional framework: integrations of alternative approaches. Discussion paper 96-t-8. Regional Economics Applications Laboratory. University of Illinois, 1996.

HADDAD, E. A. A Estrutura econômica de Minas Gerais: uma análise de insumo-produto. Revista Nova Economia, Belo Horizonte, p.11-58, 1995.

HAGUENAUER, L., BAHIA, L. D., CASTRO, P. F., RIBEIRO, M. B. Evolução das cadeias produtivas brasileiras na década de 90. Texto Para Discussão IPEA, Brasília, p.1-61, 2001.

HARRE, H., PIRSCHER, F. The food industry in the new EU member states: a comparative view on structure, conduct and performance. Outlook on Agriculture, Thousand Oaks, v.38, n.1, p.23-29, 2009.

HIRSCHMAN, A. O. The Strategy of Economic Development. New Haven: Yale University Press. 1958. 217p. 
INSTITUTO BRASILEIRO DE GEOGRAFIA E ESTATÍSTICA. Sistema IBGE de Recuperação Automática - SIDRA/IBGE. Abate de aves de corte. Brasília: Instituto Brasileiro de Geografia e Estatística, 2018. Disponível em: <http://www.sidra.ibge.gov.br/bda/tabela/protabl.asp>. Acesso em: 14 abr. 2018.

KALLUF, S. N.; KURESKI, R. Modelo insumo-produto: uma aplicação para a Economia Paranaense. Nota Técnica 25. IPARDES: Curitiba, 2014.

KALUFF, S.N. et al. A. Matriz de Insumo-Produto do Nordestes e Estados: metodologia e resultados. Banco do Nordeste: Fortaleza, 2010.

LEONTIEF, W. A economia do insumo-produto. São Paulo: Nova Cultura, 3ed., 1988. 233p.

MELLO, T. L. Defesa da concorrência. In KUPFER, D. Economia industrial: fundamentos teóricos e práticos no Brasil. Rio de Janeiro: Elsevier, 2002. p. 485-514.

MENDES, C. S.; PEREIRA, M.W.G.; TEIXEIRA, E. C. Uma análise do Insumo-Produto do setor lácteo mineiro. Revista Econômica do Nordeste, Fortaleza, v.42, n.3, p. 489-504, 2011.

MILLER, R.E.; BLAIR, P.D. Input-output analysis: foundations and extensions. New York: Cambridge University Press, 2009. 750p.

MINISTÉRIO DA INDÚSTRIA, COMÉRCIO EXTERIOR E SERVIÇOS. Comex Stat. Comércio exterior de aves de corte. Brasília: Ministério da Indústria, Comércio Exterior e Serviços, 2018. Disponível em: <http://comexstat.mdic.gov.br/pt/home>. Acessado em: 05 mai. 2018.

MOHAMED, Z. et al. Struture, conduct and performance of the Malaysian meat and meat preparation industry. Pertanika Social Sciences e Humanities, Selangor, v. 23, p.47-62, 2015.

MORIMOTO, Y. On aggregation problems in input-output analysis. Review of Economic Studies, London, v.37, n.109, p. 119-26, Jan. 1970.

MULLER, C. A., SANTOS, J. C., AGUIAR, D. R. Análise de desempenho na cadeia bovina no Estado de São Paulo. In: Sociedade Brasileira de Economia e Sociologia Rural, 44, 2006. Anais... Fortaleza: UFC, 2006.

NZIMA, W. M., DZANJA, J. Efficiency of soybean Markets in Malawi: structure, conduct and performance approach. Internacional Journal of Business and Social Science, Radford, v.6, n.4, p.162-170, 2015.

OECD-FAO. Agricultural Outlook 2016-2025. Paris: OECD Publishing/ Food and Agriculture Organization of the United Nations, 2016. doi:10.1787/agr_outlook-2016-10-em

OLIVEIRA, C. A. A dinâmica da estrutura da indústria de carne de frango no Brasil, 2011, 100 f. Dissertação (Mestrado em Agronegócios) Programa de Pós-Graduação em Agronegócios, Universidade de Federal do Rio Grande do Sul, Porto Alegre.

PORSSE, A. A. Multiplicadores de impacto na economia gaúcha: aplicações do modelo de insumo-produto fechado de Leontief. Porto Alegre: Fundação de Economia e Estatística Siegfried Emanuel Heuser, 2002. 52p.

PORSSE, A. A. Multiplicadores de impacto na economia gaúcha: aplicação do modelo de insumo-produto fechado de Leontief. Documentos FEE, n. 52, Porto Alegre: FEE, 2002.

RASMUSSEN, P. Studies in Intersectoral Relations. Amsterdam: North Holland. 1956.

RICHARDSON, H. W. Insumo-Produto e economia regional. Rio de Janeiro: Zahar Editores, 1978. 272p. 
RODRIGUES, W. O., GARCIA, R. G., NAAS, I. D., ROSA, C. O., CALDARELLI, C. E. Cadeia produtiva do frango de corte de Mato Grosso do Sul: uma análise de conduta de mercado. Organizações Rurais e Agroindustriais, Lavras, v.17, n.1, p.137-147, 2015.

SCHERE, F. M., ROSS, D. Industrial Market Struture and Economic Performance. Boston: Houghton Mifflin Company, 1990.

SEDIYAMA, A. F., CASTRO JÚNIOR, L. G., CALEGARIO, C. L., SIQUEIRA, P. H. Análise de estrutura, conduta, e desempenho da indústria processadora de soja no Brasil no período de 2003 a 2010. Revista de Economia e Sociologia Rural, Brasília, v.51, n.3, p.161-182, 2013. doi:10.1590/S0103-20032013000100009

SETIAWAN, M., EMVALOMATIS, G., LANSINK, A. O. Structure, conduct, and performance: evidence from the Indonesian food and beverages industry. Empirical Economics, Vienna, v.45, n.3, p.1149-1165, 2013.doi:10.1007/s00181-012-0648-3

SOARES, N. S., OLIVEIRA, R. J., CARVALHO, K. H., SILVA, M. L., JACOVINE, L. A., VALVERDE, S. R. A cadeia produtiva da celulose e do papel no Brasil. Revista Floresta, Curitiba, v.40, n.1, p.1-22, 2010. doi:10.5380/rf.v40i1.17094

SONIS, M.; HEWINGS, G. J.D.; GUO, J. Sources of structural changes in input-output systems: a field of influence approach. Economics System Research, Vienna, v.8, n.1, 1996.

TALAMINI, E., PEDROZO, E. Á. Matriz do tipo Insumo-Produto (MIP) de uma propriedade rural derivada do estudo de filière. Teoria e Evidência Econômica, Passo Fundo, v.12, n.22, p.77-103, 2004.

TALAMINI, E., PEDROZO, E. Á. Matriz do tipo Insumo-Produto (MIP) de uma propriedade rural derivada do estudo de filière. Teoria e Evidência Econômica, Passo Fundo, v.12, n.22, p.77-103, 2004.

TAVARES, M. C. A. Problemas de acumulação oligopólica em economias semiindustrializadas. In: MELO, H. P. Maria da Conceição Tavares: vida, ideias, teorias e políticas. São Paulo: Fundação Perseu Abramo / Expressão Popular / Centro Internacional Celso Furtado, 2019

TEIXEIRA, L. A. J. Banana. Boletim Técnico IAC. 2ed. rev. e atual. Campinas, n. 100, 1997. p. 131-132.

TOREZANI, T. A., CALDAS, B. B., CALDEIRA, J. F. Matriz Insumo Produto do RS e Brasil: Estimando os Multiplicadores Totais e os Impactos das Quebras de Safra da Soja no RS. In: Encontro de Economia Gaúcha 2016, 8, 2016, Porto Alegre. Anais eletrônicos...Porto Alegre: FEE, 2016. Disponível em: <http://cdn.fee.tche.br/eeg/8/19_BRUNO-BREYERCALDAS.pdf>. Acesso em: 05 fev. 2019.

VIAENE, J., GELLYNCK, X. Structure, Conduct and Performance of the European Food Sector. European Review of Agricultural Economics, Den Haag, v.22, n.3, p.282295,1995.

YESUFU, O. A., AYANWALE, A. B. Structure, Conduct and Profitability of broiler processing enterprises in Southwestern Nigeria. Journal of Agriculture and Environmental Studies, Madison, v.2, n.2, p.1-20, 2011.

ZYLBERSZTAJN, D. Agribusiness systems analysis: origin, evolution and research perspectives. Revista de Administração, Brasília, v.52, n.1, p.114-117, 2017. doi:10.1016/j.rausp.2016.10.004

ZYLBERSZTAJN, D. Conceitos gerais, evolução e apresentação do sistema agroindustrial. In: ZYLBERSZTAJN, D.; NEVES, M. F. (Org.). Economia e Gestão dos Negócios Agroalimentares. São Paulo: Pioneira, 2000. v. 1, cap. 1. p. 1-20. 
Apêndice I

Compatibilização da Matriz da Cadeia de frango de corte

\begin{tabular}{|c|c|c|c|c|c|}
\hline Setor & MIP MS & Setor & MIP MS & Setor & MIP MS \\
\hline \multirow{2}{*}{$\begin{array}{l}\text { Cadeia de } \\
\text { frango de } \\
\text { corte }\end{array}$} & Aves e ovos & \multirow{16}{*}{$\begin{array}{c}\text { Industria de } \\
\text { transformação }\end{array}$} & Têxtil & \multirow{2}{*}{$\begin{array}{l}\text { Industria de } \\
\text { transformação }\end{array}$} & $\begin{array}{c}\text { Aeronaves, embarcações e outros } \\
\text { equipamentos de transporte }\end{array}$ \\
\hline & Carne de aves & & Artigos do vestuário e acessórios & & Outras transformação \\
\hline \multirow{8}{*}{$\begin{array}{l}\text { Agropecuária } \\
\text { sem Aves }\end{array}$} & Milho em grão & & Calçados e artefatos de couro & \multirow{2}{*}{ SIUP } & $\begin{array}{c}\text { Eletricidade, gás e outras } \\
\text { utilidades }\end{array}$ \\
\hline & Cana-de-açúcar & & Produtos de madeira, exclusive móveis & & $\begin{array}{c}\text { Água, esgoto, reciclagem e gestão } \\
\text { de resíduos }\end{array}$ \\
\hline & Soja em grão & & $\begin{array}{c}\text { Celulose, Papel, papelão, embalagens } \\
\text { e artefatos de papel } \\
\end{array}$ & \multicolumn{2}{|r|}{ Construção Civil } \\
\hline & $\begin{array}{l}\text { Bovinos e outros animais vivos, } \\
\text { prods. animal, caça e serv. }\end{array}$ & & Serviços de impressão e reprodução & \multicolumn{2}{|r|}{ Comércio } \\
\hline & $\begin{array}{c}\text { Leite de vaca e de outros } \\
\text { animais }\end{array}$ & & Etanol e outros biocombustíveis & \multirow{4}{*}{$\begin{array}{l}\text { Transporte e } \\
\text { Armazenagem }\end{array}$} & Transporte terrestre \\
\hline & Suínos & & $\begin{array}{c}\text { Produtos químicos inorgânicos, } \\
\text { orgânicos, resinas, adubo e fertilizantes }\end{array}$ & & Transporte aquaviário \\
\hline & $\begin{array}{c}\text { Produtos da exploração } \\
\text { florestal, da silvicultura e pesca }\end{array}$ & & $\begin{array}{c}\text { Produtos químicos diversos, } \\
\text { defensivos, tintas, vernizes e esmaltes }\end{array}$ & & Transporte aéreo \\
\hline & $\begin{array}{c}\text { Outros produtos da } \\
\text { agropecuária } \\
\end{array}$ & & $\begin{array}{c}\text { Perfumaria, sabões e artigos de } \\
\text { limpeza }\end{array}$ & & $\begin{array}{c}\text { Armazenamento, serviços } \\
\text { auxiliares aos transportes e correio } \\
\end{array}$ \\
\hline \multicolumn{2}{|r|}{ Extrativa mineral } & & Produtos farmacêuticos & \multirow{2}{*}{$\begin{array}{l}\text { Alojamento e } \\
\text { Alimentação }\end{array}$} & $\begin{array}{l}\text { Serviços de alojamento em hotéis } \\
\text { e similares }\end{array}$ \\
\hline \multirow{5}{*}{$\begin{array}{l}\text { Alimentos e } \\
\text { Bebidas }\end{array}$} & \begin{tabular}{|c|} 
Carne de bovinos e outros prod. \\
de carne
\end{tabular} & & Fabr. Prod. Borracha e Mat. Plástico & & Serviços de alimentação \\
\hline & Carne de suíno & & Cimento e artefatos em cimento & \multirow{4}{*}{$\begin{array}{l}\text { Outros } \\
\text { serviços }\end{array}$} & $\begin{array}{l}\text { Serv. De informação e } \\
\text { comunicação }\end{array}$ \\
\hline & $\begin{array}{l}\text { Leite resfriado, esterilizado, } \\
\text { pasteurizado e laticínio }\end{array}$ & & $\begin{array}{l}\text { Vidros, cerâmicos e outros prod. de } \\
\text { minerais não-metálicos }\end{array}$ & & $\begin{array}{c}\text { Intermediação financeira, seguros } \\
\text { e previdência complementar }\end{array}$ \\
\hline & Açúcar & & $\begin{array}{l}\text { Ferro-gusa e ferroligas e semi- } \\
\text { acabados }\end{array}$ & & Atividades Imobiliárias e aluguel \\
\hline & $\begin{array}{c}\text { Óleos e gorduras vegetais e } \\
\text { animais }\end{array}$ & & $\begin{array}{c}\text { Produtos da metalurgia de metais não- } \\
\text { ferrosos e peças fundidas }\end{array}$ & & \begin{tabular}{|c|} 
Ativ. Prof. Cient.Tec. Adm. E Serv. \\
Complementares
\end{tabular} \\
\hline
\end{tabular}


RODRIGUES, FRAINER, EDUARDO

\begin{tabular}{|c|c|c|}
\hline $\begin{array}{l}\text { Produtos derivados do trigo, } \\
\text { mandioca ou milho }\end{array}$ & $\begin{array}{c}\text { Produtos de metal, excl. máquinas e } \\
\text { equipamentos }\end{array}$ & Administração Pública \\
\hline $\begin{array}{c}\text { Rações balanceadas para } \\
\text { animais }\end{array}$ & $\begin{array}{l}\text { Fabr. Máquinas, aparelhos e mat. } \\
\text { Elétricos }\end{array}$ & Educação e Saúde Mercantil \\
\hline Outros produtos alimentares & $\begin{array}{c}\text { Fab. Máquinas e equipamentos } \\
\text { mecânicos }\end{array}$ & $\begin{array}{l}\text { Artes, cult. Esp. Rec. E outras } \\
\text { atividades de serviços as famílias }\end{array}$ \\
\hline Bebidas & $\begin{array}{c}\text { Caminhões e ônibus, incl. cabines, } \\
\text { carrocerias e reboques }\end{array}$ & Serviços domésticos \\
\hline
\end{tabular}

Fonte: elaborado pelos autores. 


\section{Apêndice II}

Matriz insumo-produto de Mato Grosso do Sul 11x11, 2015

\begin{tabular}{|c|c|c|c|c|c|c|c|c|c|c|c|}
\hline Setor & $\begin{array}{l}\text { Cadeia de } \\
\text { frango de } \\
\text { corte }\end{array}$ & $\begin{array}{l}\text { Agropecuária } \\
\text { sem Aves }\end{array}$ & $\begin{array}{l}\text { Extrativa } \\
\text { Mineral }\end{array}$ & $\begin{array}{l}\text { Alimentos e } \\
\text { Bebidas }\end{array}$ & $\begin{array}{l}\text { Industria de } \\
\text { transformação }\end{array}$ & SIUP & $\begin{array}{l}\text { Construção } \\
\text { Civil }\end{array}$ & Comércio & $\begin{array}{c}\text { Transporte e } \\
\text { Armazenagem }\end{array}$ & $\begin{array}{l}\text { Alojamento e } \\
\text { Alimentação }\end{array}$ & $\begin{array}{l}\text { Outros } \\
\text { serviços }\end{array}$ \\
\hline $\begin{array}{l}\text { Cadeia de frango } \\
\text { de corte }\end{array}$ & 266 & 30132 & 0 & 98710 & 31832 & 6 & 124 & 2069 & 0 & 447 & 344 \\
\hline $\begin{array}{l}\text { Agropecuária sem } \\
\text { Aves }\end{array}$ & 30132 & 3413516 & 8 & 11182278 & 3606088 & 699 & 13998 & 234347 & 0 & 50596 & 38974 \\
\hline Extrativa mineral & 328 & 37150 & 68226 & 8789 & 634649 & 331594 & 156114 & 51468 & 72 & 0 & 7263 \\
\hline $\begin{array}{l}\text { Alimentos e } \\
\text { Bebidas }\end{array}$ & 10203 & 1155788 & 122 & 2047632 & 584860 & 0 & 0 & 175955 & 962 & 545576 & 160794 \\
\hline $\begin{array}{l}\text { Industria de } \\
\text { transformação }\end{array}$ & 65526 & 7423084 & 214344 & 530013 & 6583342 & 664628 & 3515359 & 1575007 & 1903636 & 79387 & 1653779 \\
\hline SIUP & 5686 & 644157 & 12483 & 140614 & 419599 & 1761905 & 14536 & 382651 & 48274 & 37990 & 639322 \\
\hline Construção Civil & 160 & 18101 & 14836 & 35 & 7834 & 79370 & 1040445 & 17165 & 20738 & 5731 & 421379 \\
\hline Comércio & 131 & 14831 & 4535 & 3238 & 297609 & 18086 & 8937 & 153454 & 93966 & 651 & 117665 \\
\hline $\begin{array}{l}\text { Alojamento e } \\
\text { Alimentação }\end{array}$ & 5 & 578 & 2829 & 630 & 28425 & 11074 & 7095 & 25592 & 17110 & 2812 & 318725 \\
\hline Outros serviços & 3631 & 411336 & 201937 & 199788 & 1707122 & 613294 & 499647 & 2796206 & 842666 & 147083 & 8513972 \\
\hline
\end{tabular}

Fonte: elaborado pelos autores. 


\section{Apêndice III}

Figura 2. Localização e detalhamento da cadeia produtiva de frango de corte em Mato Grosso do Sul.

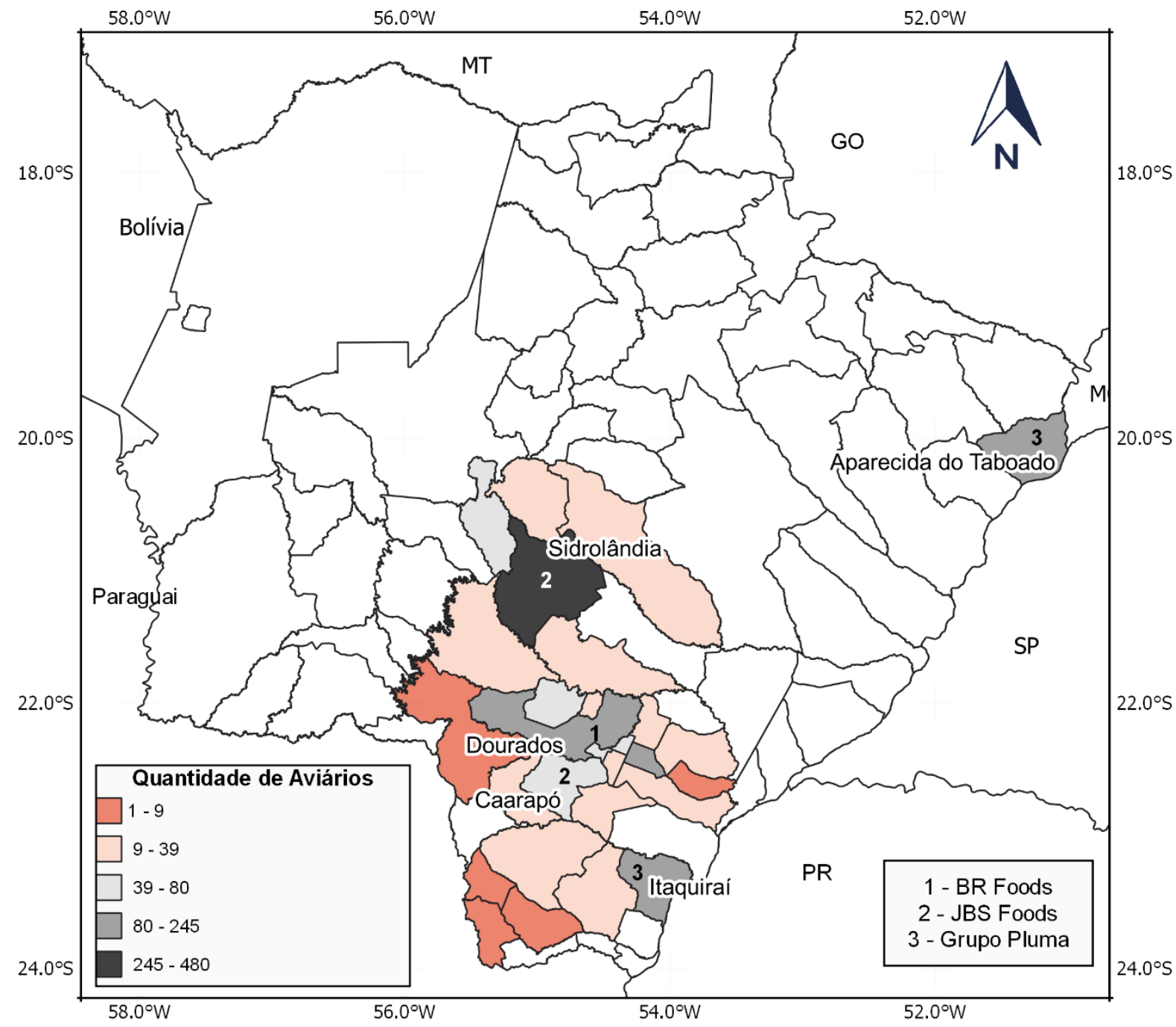

Fonte: elaboração própria com base nos dados da pesquisa. 


\section{NOTAS DE AUTOR}

\section{CONTRIBUIÇÃO DE AUTORIA}

Wesley Osvaldo Pradella Rodrigues - Concepção, Coleta de dados, Análise de dados, Elaboração do manuscrito, revisão e aprovação da versão final do trabalho.

Daniel Massen Frainer - Concepção, Coleta de dados, Participação ativa da discussão dos resultados. Revisão e aprovação da versão final do trabalho.

Antonio Sérgio Eduardo - Coleta de dados, Participação ativa da discussão dos resultados, Revisão da versão final do trabalho.

\section{FINANCIAMENTO}

Não se aplica.

\section{CONSENTIMENTO DE USO DE IMAGEM}

Não se aplica.

\section{APROVAÇÃO DE COMITÊ DE ÉTICA EM PESQUISA}

Não se aplica.

\section{CONFLITO DE INTERESSES}

Não se aplica.

\section{LICENÇA DE USO}

Este artigo está licenciado sob a Licença Creative Commons CC-BY. Com essa licença você pode compartilhar, adaptar, criar para qualquer fim, desde que atribua a autoria da obra.

\section{HISTÓRICO}

Recebido em: 03-04-2020

Aprovado em: 09-06-2020 